\title{
LA ENSEÑANZA DE LA HISTORIA Y EL DESCUBRIMIENTO DE AMERICA**
}

Conferencia dictada por el doctor Jorge Mora Forero, Profesor de la Universidad Pedagógica Nacional el 10 de mayo de 1991, en el marco de la Feria Internacional del Libro celebrada en Bogotá.

Cuando uno tiene que tratar el asunto de enseñar historia, es inevitable que venga a la memoria el recuerdo de su propia experiencia en el campo del aprendizaje de dicha asignatura.

Y refiriéndome concretamente a lo que antes se llamaba primaria y bachillerato, todo lo que recuerdo de historia se reduce a dos cosas: en la primaria, dos pequeños paisajes; el primero de ellos repres entaba a dos figuras humanas: la de Vasco Núñez de Balboa, enfundado en su vestido de conquistador, con grandes botas que iban más arriba de la rodilla, coraza y casco, "descubriendo el Mar del Sur, bien metido dentro de él, blandiendo en una mano el estandarte de Castilla y en la otra su espada, tomando posesión del citado mar, en nombre de los Reyes, sus señores.

Atrás, de lejos, se veía la figura semidesnuda de Panquiaco, el joven indígena que le mostró a Vas co Núñez de Balboa el Mar del Sur para que lo "descubriera".

El segundo paisaje era la repres entación de la fundación de Santafé de Bogotá, por Gonzalo Jiménez de Quesada, justo al lado de donde los indígenas tenían su aldea denominada Bacatá.

Los anteriores paisajes estaban incrustados en dos medias páginas de un pequeño folleto que una Hermana de la Presentación, nuestra directora y profesora, nos hacía aprender de memoria en aquellos ratos en que no estábamos en el patio desfilando con nuestros uniformes verde oliva de soldados infantiles, empuñando fusiles de madera y marchando al son de la banda de guerra (no había entonces bandas de paz), y bajo la ordenadora voz de un reservista del ejército que acababa de regresar de su lucha contra las guerrillas liberales, denominadas entonces, por el gobiemo y por nues tra monjita, "la chusma".

Todavía resuena en mis oídos aquella voz varonil. . . "quier. . . dos. . . tres. . . cuatro. .. quier. . dos ... tres..., cuatro, descansen ... jar!... ¡A discreción!... y ahora... ja cantar, muchachos!

\footnotetext{
* Profesor de istoria de la Universidad Pedagógica Nacional.

** Algunos de estos temas se encuentran estudiados con más profundidad en el libro La enseñanza de la historia y la educación en Colombia, Bogotá, Ecoe Ediciones, 1988.

Aparecía el fundador con un fraile, varios soldados españoles y una cantidad de indígenas que miraban, desde la parte posterior, las doce chozas pajizas que ellos mismos habían construido.
} 
Y comenzábamos a cantar lo que entonces era nuestro himno de guerra y símbolo de lealtad a la España franquista, el himno a Cristo Rey: "Tú reinarás, este es el grito, que ardiente exhala nuestra fé.

En la secundaria, mi recuerdo se reduce a una página de un texto de historia universal que contenía una leyenda alusiva a cómo los judíos en España en la época de los Reyes Católicos, se robaban a los niños cristianos recién nacidos, quienes eran sacrificados y comidos en banquetes de media noche. Por eso los habían desterrado.

Recuerdo que, paralelamente a mis estudios de historia universal, en la secundaria que cursaba con religiosos, volví a cantar el "Tú reinarás", esta vez con motivo de la invasión a Bahía Cochinos, para suplicar a Dios que ayudara a los.., libertadores que venían de Miami a tumbar a quien se denominaba "el tirano Castro".

Lo anterior, unido al hecho de que crecí en medio del fuego cruzado de la violencia liberal-conservadora, me hizo vivir una experiencia que me dejó marcado durante mucho tiempo y, en algunos as pectos, para toda la vida.

Aprendí entonces, que los hombres se dividían en dos grupos: los buenos y los malos. Los malos eran, porsupuesto, los que no pensaban ni actuaban como yo.

Me ocurrió lo que, según el profesor R. G. Collingwood, le ocurre a aquellos que reciben la formación histórica en la primaria y el bachillerato: se vuelven personas dogmáticas. Decía Collingwood:

Todo conocimiento adquirido por vía de educación trae aparejada una ilusión peculiar, la ilusión de lo definitivo. Cuando un estudiante está in statu pupilari respecto a cualquier materia, tiene que creer que las cosas e stán bien establecidas, puesto que sus libros de texto y sus maestros así las consideran. Cuando por fin sale de ese estado y prosigue el estudio por su cuenta, advierte que nada está finalmente establecido, y el dogmatismo, que siempre es señal de inmadurez, lo abandona. Considera entonœs, a los llamados hechos bajo una nueva luz y se pregunta si aquello que su libro de texto y su maestro le enseñaron como cierto, realmente lo es ${ }^{1}$.

Pero Collingwood quedaba también muy preocupado porque el estudiante bien podría quedarse siempre, y creemos que ocurre en la mayoría de los casos, in statu pupilari, con relación a su concepción del mundo. Además, el hacer estudios universitarios, si es que se tiene la oportunidad, no garantiza, de por sí, un cambio de mentalidad en el educando, y es más, a veces afirma el dogmatismo, o crea nuevos dogmatismos y ésto aun estudiando ciencias sociales. Y lo que es más grave: a veces los mismos profesores no estamos exentos de sustentar estos dogmatismos.

En cuanto a mi propia experiencia, puedo decir que, en general, los estudios histórico-sociales universitarios, abrieron mis ojos para ver una nueva realidad: el

${ }^{1}$ R. G. COLLINGWOOD, Idea de la Historia, México, PCE., 1974, págs. 17-18. 
hombre como ser his tórico, por lo tanto cambiante y relativo, conociendo el mundo y conociéndose a símismo desde un proceso de transformación permanente que lo convierte en algo indeterminado, en un ser que va siendo, como dice un filósofo. Puedo considerame un afortunado, porque, como decía antes, no siempre ocurre así en los estudios superiores, y menos aún, en la educación secundaria, en la cual, y con un alto grado de certeza, todas las afimaciones de los maestros y de los libros de texto se consideran como verdades indiscutibles y la historia se considera como una costura.

No deben sorprendernos, pues, las respuestas que dan los estudiantes de bachillerato y de universidad, al ser interrogados sobre su experiencia en el aprendizaje de la historia. Los estudiantes de bachillerato dan respuestas como éstas:

Los temas son repetidos y aburridos. No son útiles en la vida.

Los textos son largos, hartos y confusos.

Para estudiar medicina o derecho, no se necesita historia, no nos sirve para nuestra vida social, ni para los estudios, ni en ninguna parte.

Es importante por cultura general y para el examen del ICFES, pero para mi vida futura, no me importa? ${ }^{2}$.

Veamos ahora lo que contestan algunos estudiantes de Ciencias Sociales de la Universidad Pedagógica a la pregunta sobre los problemas que presenta la enseñanza-aprendizaje de la Historia:

Mi relación con la historia, al menos hasta el bachillerato, ha sido simplemente el conocimiento de un anecdotario de personajes míticos, de sus hechos sobresalientes pero que no dejaron en mi el reconocimiento de mi propia historicidad; fue la negación de mi propia trascendencia en favor del personaje que asumía el control y la vivencia de la historia ${ }^{3}$.

La historia, desafortunadamente, en la mayoría de las veces, se ha enseñado como una serie de hechos aislados sin relación alguna con el presente, deteniéndose solamente en simples relatos, fechas y nombres, como ejercicio de memorización, sin cabida al análisis ni a la reflexión ${ }^{4}$.

La experiencia en el aprendizaje de la historia, fue, por no decir, completamente limitada por las razones político-sociales del contexto donde se desenvuelve. A veces ha sido (refiriéndome a los pros) un aprendizaje, crítico, analítico y dialéctico, que me lleva a una comprensión total de los temas, pero, en otras oportunidades (refiriéndome a los contras) ha sido un conocimiento magistral y memorístico, el cual desecha el análisis y la crítica que ayudan a forjar un criterio

\footnotetext{
${ }^{2}$ Ver JORGE MORA FORERO, La Enseñanza de la Historia de la Educación en Colombia, Bogota, ECOE, 1988.

${ }^{3}$ ALFONSO ROBAYO, Cuestionario, Curso América 1, Ciencias Sociales U. P., Nal., 1991.

${ }^{4}$ NELLY CARRANZA, ibidem. 
propio. En la universidad se presentan estos dos casos, lo cual es deplorable, pues esto crea un ambiente no propicio para el ahondamiento de la investigación que estanca el avance educativo ${ }^{5}$.

El programa es extenso y siempre queda inconcluso.

El problema fundamental en la Universidad es el carácter que le dan algunos maestros a la enseñanza de la historia, puesto que la toman como una asignatura narrativa y enunciativa de hechos, dejando de lado un análisis riguroso; ob viamente, esto no sucede en todos los casos.

Otro problema es que algunas veces el estudio de la historia se jimita solamente a leer y leer para luego escribir y escrib ir en una hoja lo que se leyó, sin saber ni qué se leyó ni qué se estudió.

No se tiene un claro conocimiento de las escuelas históricas, entonces no distinguimos entre un autor positivista y uno presentista.

Se debe fomentar la discusión. Muchos profesores no permiten una intervención para criticar o analizar lo que se está diciendo ${ }^{6}$

Lo anterior nos está mostrando que como maestros no tenemos una conciencia clara acerca de lo que la historia, como conocimiento del pasado significa para explicar nuestro presente y para proyectar nuestro futuro. Pero esto nos indica también que, en modo alguno, tenemos entre manos un proyecto pedagógico, en el sentido de la Paideia griega, en la cual la educación implica una formación integral del hombre y no solamente enseñanza o instrucción. Francisco Cajiao, hace bien esta diferencia en un libro dedicado al tema, cuando nos dice que la educación hace referencia a una tarea de integración de la persona, mientras que la enseñanza se refiere a la comprensión intelectual de ciertos campos del saber?

En el mismo sentido se manifiesta Alberto Merani cuando dice que "la pedagogía está imbuída de didáctica; hace creer al maestro que los medios para educar son idénticos a los fines de la educación, y por este camino llega a pensar que la más perfecta de las didácticas, que la escuela que mas cosas enseña y más científicamente lo hace, es la mejor"8.

Lo anterior nos hace comprender que para que la enseñanza sea realmente eficaz, debe constituirse en parte vital del proceso educativo con un proyecto pedagógico que tenga como objetivo formar hombres socialmente nuevos, capaces de analizar y transformar el mundo en crisis en que estamos viviendo.

\footnotetext{
${ }^{5}$ VILMA SUÁREZ, Curso de Historia Greco-romana, Ciencias Sociales, U. P. N., 1991.

${ }^{6}$ JORGE MORA FORERO, Op., cit., págs. 25-26.

${ }^{7}$ FRANCISCO CAJIAO, Pedagogía de las ciencia, sociales, Bogotá, Intereditores, S. A., 1989, pág. 20.

${ }^{8}$ ALBERTO MERANI, Educación y Relaciones de Poder, México, Grijalbo, 1980, pág. 40. 
Y esta imagen del hombre que buscamos, dice Francisco Gutiérrez, que "hemos de trazarla, por tanto, con los ras gos a que nos obligan las contradicciones del presente, sumados a los que nos permita vislumbrar ese caminar hacia la sociedad del futuro. Es en el presente que nos amarra y estruja fuertemente a la realidad y en el futuro que nos impulsa a superar las paradojas del presente, en donde se encierra la polaridad que nos obliga a la conquista de 'un hombre cada vez más hombre' y de 'una vida humana cada vez más humana'”?

Entendida la educación, no como un simple proceso adaptativo sino como un proceso de creatividad personal y por tanto histórica, "no es un medio para prever el futuro probable sino un recurso para preparar el futuro deseable. Es en cierta forma, una posibilidad de ruptura con las injusticias del presente y una responsabilidad de acción cons ciente y deliberada para conquistar el mañana"10.

Dentro de este contexto, vamos a hacer nuestra reflexión sobre la enseñanza de la his toria partiendo de una premisa fundamental: haciendo un acto de fe en el hombre, creemos que nuestro trabajo, la enseñanza en general y la enseñanza de la historia en particular, tiene sentido.

Nosotros los maestros podemos parodiar a Shakespeare y decir: "enseñar o no enseñar, hé ahí el dilema"; dilema radical para los educadores que afrontamos el trabajo de transmitir la cultura y de reflexionar y actuar sobre ella como producto histórico que es.

Entremos pues al proceso del aprendizaje y digamos con Pablo Freire ${ }^{11}$ que aprender:

- No consis te en depositar contenidos de conocimiento en un recipiente vacío.

- No es que el alumno copie en su mente los conocimientos del educador.

- No es leer muchos libros.

- No es memorizar.

- No es obtener la más alta calificación.

- No es s implemente estudiar.

Es un proceso complejo, laborioso y difícil de transformación del sujeto mismo en el cual hay una modificación de la conducta.

Modificación que hace referencia, o bien a que reafirma conscientemente sus creencias y actitudes anteriores, o que adquiere nuevas creencias y se expresa con nuevas actitudes.

\footnotetext{
${ }^{9}$ FRANCISCO GUTIERREZ Educación como Praxis Política, México, S. XXI, 1985, pág. 71.

${ }^{10}$ VÍCTOR GUÉDEZ, Educación y Proyecto Histórico Pedagógico, Caracas, Kapeluz, 1987, pág. 29.

11 Ver PABLO FREIRE, La Educación como Práctica de la Libertad, Santiago de Chile, ICIRA, 1969.
} 
En el proceso de aprendizaje es fundamental la praxis. Y praxis es un proceso que implica acción-reflexión, reflexión-acción. Es un proceso dialéctico. Es decir, la praxis no es cualquier práctica, es una práctica a la que se llega después de un proceso reflexivo.

Con ello queremos dejar en claro que el educando "no aprende porque se le dicen las cosas ni siquiera porque se le muestran, aprende porque actúa sobre ellas y las vive. De esta forma el alumno es realmente el sujeto de su propia educación"12.

Sobre la anterior premisa debe orientarse la enseñanza de la historia.

Pero ¿cómo entendemos nosotros la historia que vamos a enseñar? La entendemos como la acción humana, la acción de todos los hombres, a tra vés del tiempo y del espacio y también como la reflexión que realizan los hombres sobre dicha acción.

Aquí tenemos dos conceptos interrelacionados: acción y reflexión.

La acción humana son todos los hechos sociales, el desarrollo objetivo del proceso histórico que se convierte en objeto de reflexión.

La reflexión es el proceso, es la toma de conciencia que hace el hombre sobre su proceso de desarrollo.

De acuerdo con las respuestas que han dado los estudiantes, resulta que muchas veces se concibe a la historia:

- Como un proceso que realizan con su extraordinaria voluntad ciertos grandes hombres: "La his toria la escriben los héroes".

- Como la descripción ordenada y sistemática de hechos, lugares y nombres.

- Como un pasado remoto e inerte que ha dejado de existir.

- Como un presente al que somos extraños.

- Como una memoria social" donde se han registrado datos que podemos consultar ${ }^{13}$.

- O como una asignatura que no tiene ninguna importancia pero que hay que tolerar dentro de un programa de estudios. Así lo entiende la sociedad, y lo que es más grave, así muchas veces lo entienden los maestros de his toria.

Lo anterior no conduce a nada mientras no se entienda que la historia no es ajena a quien la estudia; que el sujeto que la estudia es el mismo sujeto de la historia. Que la historia debe estudiarse para explicar el presente y transformarlo ya que ella es una construcción humana. La his toria es la dinámica del hombre.

\footnotetext{
12 MARTIN ARREDONDO y OTROS, Manual de Didáctica de las Ciencias Histórico-Sociales, México, UNAM, 1972, pág. 9.

${ }^{13}$ Ibidem, pág. 14.
} 
Pero para llegar aquí, el maestro debe estar preparado teóricamente, porque cuando ello no ocurre, al carecer de una teoría que explique el funcionamiento y desarrollo de la sociedad a través del tiempo, el maes tro se ve abocado a utilizar la narración burda y la memorización exhaustiva como método para la enseñanza de la materia, con lo cual lo único que obtiene son resultados completamente negativos.

El estudiante acabará por detestar la materia y al profesor y ya no le dará ninguna importancia al estudio de la historia. Porque si la historia es un pasado muerto ¿qué sentido tiene estudiarlo y reflexionar sobre él? Si la historia consis te en un aprendizaje memorístico de héroes, de fechas, de reyes o presidentes y de dinastías que a nadie importan ¿quién querría aprenderse esas interminables listas?

Refutando el concepto de historia como pasado muerto, dice el conocido pensador Benedetto Croce, poniendo como ejemplo a la civilización griega:

Cuando el desarrollo de las culturas de mi momento histórico abre ante mí el problema de la civilización helénica, de la filosofía platónica, o de un aspecto particular de la vida ática, ese problema se halla tan ligado a mi ser como la historia de un negocio que estoy tratando, de un amor que estoy cultivando con la misma ansia, me atormenta la misma conciencia de la infelicidad hasta que llego a resolverlo.

La vida helénica se halla en este caso presente en mí y me solicita, me atrae o me atomenta, con el rostro del adversario, de la mujer amada o del hijo predilecto por el cual se tiembla ${ }^{14}$.

En cuanto a la historia heroica, el es pecialis ta Franco Catalano nos dice que es indudable que esta concepción del individuo excelso, capaz, con su sola voluntad, de crear o de modificar el cuerpo de los acontecimientos, entraña cierta dosis de irracionalismo, del irracionalismo típico de los comienzos de este siglo, e incluso de historiadores más antiguos como Maquiavelo, con su exaltación del Príncipe. Agrega que de lo que se trata en estos casos es de una incapacidad fundamental para ver a los sectores integrados en una realidad social compleja, de una confianza ciega (se diría supersticiosa) en la intervención del ser dotado de cualidades sobrenaturales para interrumpir la continuidad efectiva de la his toria ${ }^{15}$.

La enseñanza de la historia en nuestro medio está saturada de todas estas deficiencias como bien lo explica el profesor Estanislao Zuleta en uno de sus escritos ${ }^{16}$.

${ }^{14}$ BENEDETTO CROCE, Teoría e Historia de la Historiografía, Buenos Aires, Editorial Escuela, 1955, págs. 12-13.

${ }^{15}$ FRANCO CATALANO, Metodología y Enseñanza de la Historia, Barcelona, Ediciones Península, 1980 , págs. 47-48.

${ }^{16}$ ESTANISLAO ZULETA, "La educación un campo de batalla", en Revista de Educación y Cultura, $\mathrm{N}^{9} 4$, Bogotá, FECODE, pag, 41 
Así, pues, la historia no es un pasado muerto, ni la hacen solamente los llamados héroes. La historia es un pasado vivo en tanto se constituye en presente. Y la hacen todos los hombres, no solamente unos pocos.

Y estudiamos historia, por un lado, para explicarnos el presente, que es resultado del pasado, y por otro, para explicarnos la actuación de los hombres a través del tiempo y del espacio, a nivel de su vivencia real, y a nivel de las ideas que tienen sobre dicha vivencia.

La finalidad última del estudio de la historia es, desde luego, la de que aprendiendo del pasado, podamos evitar los errores cometidos y construir un mundo más humano.

Estudiar historia es estudiar la totalidad social a través del tiempo y del es pacio, es estudiar al hombre en sus múltiples relaciones: económicas, políticas e ideológicas.

En la ens eñanza de las ciencias sociales y, por lo tanto, de la his toria, hay que tener en cuenta varios puntos. El primero tiene que ver con la cientificidad del conocimiento social; el segundo con la relatividad y la parcialidad de ese conocimiento, y el tercero con su utilidad.

En el campo de la historia, el maestro debe estar preparado para abordar los hechos y procesos históricos desde diferentes teorías, las mismas que expondrá ante los alumnos incitándolos a confrontarlas con la realidad. Y esto, desde la teoría de la historia de los grandes hombres, pasando por las teorías institucionales, has ta llegar a las teorías de la historia total.

Lo que de todas maneras es importante, es que el maes tro no trate de imponer ninguna teoría, cayendo en situaciones dogmáticas que conduzcan al fanatismo. Peligro éste muy común en nues tras cátedras de Ciencias Sociales.

Olvidando la relatividad del conocimiento, y el verdadero papel del maestro como creador de condiciones para lograr una conciencia crítica, los maestros muchas veces destruimos dogmas y los reemplazamos con otros; derruímos viejas Iglesias y sobre ellas construimos las nuestras, criticamos inquisiciones pero aplicamos los cepos a aquello que no esté de acuerdo con nosotros. Y nos convertimos en guías y maestros de verdades incuestionadas e incuestionables.

Aquí bien vale la pena recordar las palabras del profesor Rodolfo de Roux, en un tiem po colega nuestro en el trabajo de la didáctica, cuando dice al respecto:

La nostalgia de absolutos nos acompaña desde los albores de la humanidad. Las angustias del presente y la incertidumbre del futuro nos abren a los dioses. Aun los ateos tienen sus santos y erigen sus capillas que llenarán prosélitos bien dispuestos a la veneración y al culto de nuevos 
fetiches. Cuán fácilmente se olvida que la verdad no se colgó jamás del brazo de un incondicional ${ }^{17}$.

Y agrega más adelante: "Cualquier único punto de vista que pretenda tener la verdad sobre el hombre y el sentido de la historia, se vuelve peligroso, por intolerante y fanático, una vezque adquiere el poder real de forzar las conciencias y violentar los cuerpos. Las ideologías religiosas y políticas ofrecen abundantes ejemplos" $"$.

No es que se le exija al maes tro ser apolítico porque eso es imposible, máxime cuando tenemos como objetivo de las ciencias sociales, y por lo tanto, de la historia, dar una verdadera fomación política para lograr ciudadanos socialmente responsables; pero la mejor política para el maestro en su cátedra, consiste en exponer todas las teorías y en desafiar a los alumnos a que las confronten con la realidad y saquen lo positivo que tengan, y encuentren también las insuficiencias o puntos débiles de cada una de ellas.

Esto del enfoque pluralista en la cátedra se ha debatido mucho. Hace poco tiempo se realizó un encuentro organizado por el "Magazín" de El Espectador. Alí varios de los participantes se expresaron en forma favorable al pluralismo. Decía el Presidente de la Academia Colombiana de Historia, Germán Arciniegas:

Sería monstruoso que las academias se cerraran para que no hubiera pluralidad en la interpretación de los hechos del pasado...

Los profesores Mauricio Archila y Daniel García trataron de ir al fondo del asunto; según ellos, el problema fundamental de la historia no es el de lograr la certeza de algunos datos o anécdotas o el de descubrir la verdad de la historia, sino el de establecer el principio de la pluralidad de interpretaciones de la historia como fundamento de la cultura, es decir, como parte esencial de una sociedad que se valora a sí misma y se afima en la carta fundamental como democrática. Por eso afimaba García:

El fin mismo de la enseñanza de la historia es que el estudiante se pregunte sobre su país, y sobre su pasado. Si él llega a concluir que tiene razón el marxista o el no marxista, ya es problema individual de la democracia, pero cerrarle la posibilidad de la discusión en la escuela, me parece fatal; criticar no es atacar, es abrir los ojos o tratar de entender la complejidad del proceso con mas elementos ${ }^{20}$.

Y concluía Mauricio Archila, sobre su papel como historiador y como profesor de historia: "No pretendo la búsqueda de la verdad sino de las verdades, porque

17 RODOLFO DE Roux, Elogio de la incertidumbre, Bogota, Editorial Nueva América, 1988, págs. 14-15.

${ }^{18}$ Ibídem, pág. 17.

${ }^{19}$ Varios, "El Debate de la Historia: dialogar ante la intolerancia", en El Espectador, Magazín Dominical $\mathrm{N}^{9} 316,30$ de abril de 1989.

${ }^{20}$ Ibidem, pág. 10. 
parto del supuesto de que no existe una verdad absoluta his tórica. Esa es un poco la tragedia tanto de una historia patria mal entendida como, si se quiere, de una historia politizada"21.

La existencia de diferentes interpretaciones de la historia, nos está mostrando la relatividad y la parcialidad de este conocimiento. Y ello se explica por el objeto de estudio de la historia; las relaciones entre los hombres, que nomalmente son relaciones conflictivas, relaciones que son captadas por el historiador que foma parte de un grupo social deteminado, con una visión del mundo, unos intereses y unos sentimientos de los cuales no puede desprenderse para elaborar un conocimiento "neutro", aséptico.

Lo que hemos venido comentando, justifica la aceptación de una pluralidad de pensamiento acerca de la his toria. No hay una verdad de la his toria; hay diferentes interpretaciones de ella. Si una de ellas se convierte en "verdad oficial", ya sea a partir del Estado o en la cátedra misma, la historia se "sacraliza", el pensamiento se estanca y la crítica, base de todo progreso o adelanto, se anula.

La sociedad comienza a mostrar, entonces, las orejas y los colmillos del monstruo totalitario, y la inteligencia tiene que entrar en receso y esconderse en las sombras del anonimato o del silencio.

Un caso de historia "sacralizada" es el de la historia heroica, la historia convertida en biografías de grandes personajes, que los estudiantes deben aprender de memoria. Alí, la historia la hacen los grandes hombres, a quienes se muestra como modelo de todas las virtudes, como semidioses o como dioses, olvidando lo más interesante de ellos: su humanidad. Por eso, cuando un historiador o un literato tratan de mostrar esa faceta de los grandes personajes, se pone el grito en el cielo, se censura en nombre de la democracia, y en nombre de la democracia se entierran sus propios valores.

Es obvio que la sacralización de la historia, tiene una función: conservar la sociedad tal como esta; es más, tal como la dejaron los héroes.

Sacralización y cambio social son conceptos antagónicos. Aquí el mito cumple su papel fundamental: lo que es bueno es lo que se hizo al principio, lo que hicieron los héroes. Lo que viene después seré bueno si es repetición de ello. El presente es bueno si repetimos el pasado; el futuro lo será si tomamos el pasado como modelo 22 .

Es la concepción de la historia que toma el pasado como futuro.

${ }^{21}$ Ibidem, pág. 7.

22 Ver M. ELIADE, El Mito del Eterno Retorno, Madrid, Alianza, 1984. 
Nosotros creemos que el papel del profesor de historia, es el de, junto con sus alumnos, enfrentarse con el pasado, que es su propio pasado, para analizarlo y explicarlo, y así, poder explicarse a la vez, su propio presente.

Este pasado no puede ser el pasado de un hombre, ni de unos cuantos hombres, sino del hombre en su plenitud social, es decir, de todos los hombres que conforman el momento y el marco histórico que se estudian.

La biografía es importante, siempre y cuando se estudie a los personajes en su contexto social. En otras palabras, se trata de entenderlos con sus propios defectos, méritos y virtudes individuales, pero también como expresiones de su época y de sus pueblos.

Y se trata de estudiar también a esos pueblos, de hacer esa que Unamuno llamaba "profunda historia de hechos permanentes, historia silenciosa, la de los pobres labriegos, que un día y otro, sin descanso, se levantan antes que el sol a labrar sus tierras, y un día y otro son víctimas de las exacciones autoritarias" ${ }^{23}$.

Así pues, la historia es historia de personajes e historia de masas, historia de mujeres e historia de hombres, de hombres de todas las razas, sin excepción: historia de quienes tienen el poder por el mango y de quienes no lo tienen; de los que trabajan y de los que no trabajan, es tos últimos, bien sea porque no necesitan trabajar, o bien, porque la sociedad les niega su derecho al trabajo. La historia tiene que ser la historia de todos los hombres organizados socialmente: en su economía, en sus clases sociales, en su organización política, en sus mentalidades. Todo ello captado en una interdependencia. La historia es, en definitiva, his toria SOCIAL.

Para que los estudiantes lleguen a aprehender el pasado en toda su complejidad, se hace necesario que el maestro busque e implemente todos los métodos e instrumentos didácticos a su alcance, con el fin de que los muchachos, conscientes de que son parte ele la historia, no pierdan en ningún momento, y al contrario, aumenten su interés por estudiarla.

Cualesquiera sean los métodos escogidos, científicos y didácticos, es fundamental la participación de los estudiantes quienes deben disfrutar de la libertad de pensamiento y de expresión para cuestionario todo, inclusive al maes tro mismo, generando sus propias teorías u opiniones y acostumbrándose a sustentarlas en la realidad histórica y acostumbrándose, también, al diálogo, al respeto por las opiniones de los otros.

El diálogo es, en efecto, la forma del lenguaje humano en la que el hombre se mues tra como tal y se diferencia de las bestias.

\footnotetext{
23 'MIGUEL DE UNAMUNO, citado por MANUEL TUÑON DE LARA en Metodología de la Historia Social de España, México S. XXI, 1973, pág. 11.
} 
Dialogar es reconocerse social, es reconocer al otro como parte fundamental de nosotros mismos.

El diálogo es la única alternativa humana y eficaz contra la fuerza bruta, pues ésta es, justamente, la negación de toda racionalidad.

Dialogar es ser humano, y la humanidad es el principio de toda sabiduría...

La literatura, la televisión, la prensa, los libros de texto y el museo, son instrumentos muy importantes en la enseñanza de la historia.

La creación literaria es, a la vez, un producto de la historia y una manera de verla. Es, en todo caso, una manera de ver el mundo, de aprehenderlo a través de la imaginación y del sentimiento.

La creación literaria aporta al conocimiento humano, y es en este sentido una fuente para el historiador y para la enseñanza de la historia, ese conocimiento que no da la historia formal con sus fríos datos, nombres y análisis de estructuras: el ambiente espiritual de un individuo o de una época, con sus sentimientos, sus pasiones, sus angustias y sus esperanzas. Eso que no queda en los documentos y que no se encuentra en ningún archivo, pero que forma parte vital de la existencia humana, muchas veces más importante que todo lo que encontramos en los documentos.

Es por eso que, algunas veces, sentimos que aprendemos mas historia en las novelas históricas que en muchos libros de historia que son verdaderos monumentos al aburimiento, llenos de datos, de nombres, ele fechas y de números que no llegan a tocar jamás la epidemis de la composición humana...

Nadie puede ignorar la importancia de la televisión en el mundo en que vivimos. El televisor se nos ha convertido en un pariente mas, en un familiar que hay que acomodar en uno ele los mejores sitios de la casa. A veces, es el único familiar con quien compartimos esa angustiosa soledad que produce la vida moderna con su sociedad de masas, des personalizada y despersonalizante.

Podemos pasar horas y horas "monologando" con ese aparato que parece tener vida propia, imagen propia, personalidad propia; que nos aconseja todos los días qué debemos comer, cómo debemos vestir, qué cosas debemos comprar, y... qué debemos pensar, para ser verdaderos hombres. "Haga como yo", es el mensaje del éxito; de un éxito que se pretende puede ser universal.

$\mathrm{Ni}$ los maestros ni los padres de familia nos hemos dado cuenta del poder transformador de la televisión. Los anunciadores, los vendedores de todo tipo de mensajes, sí se han dado cuenta de ello.

La televisión puede convertirse en un instrumento deshumanizante o humanizante, según el us o que le demos. Deshumanizante si convierte a los seres humanos en autómatas, acríticos, retrasados mentales. Humanizante, si nos acostumbramos a leer los mensajes, descifrar sus códigos, a dejar de lado lo 
banal y lo alienante y a elaborar y emitir mensajes que conduzcan a un enriquecimiento cultural.

Uno de los problemas que tiene la televisión, según un especialista es que como medio icónico presenta las imágenes de la realidad que caracterizan al objeto referido. El carácter natural que se le atribuye a la imagen del televisor no es una característica que provenga de la imagen en sí, sino de factores culturales; esta novedad reside en que, por primera vez, se tiende a concebir lo natural como un tipo de medio fabricado tecnológicamente. Este realismo que las imágenes cobran para el espectador es lo que explica que en el medio colombiano, la gente involucra la ficción y sus personajes en la vida cotidiana, y que se hable de ellos como si se tratara de miembros reales de la sociedad ${ }^{24}$.

Frente a este hecho sólo queda la desmitificación: enseñar a los alumnos a recibir críticamente el mensaje, o los mensajes, mostrando lo abierto y lo oculto, las contradicciones, los intereses particularistas que subyacen a la supuesta búsqueda de nuestro bienestar.

En casos extremos, se puede llevar un actor al salón de clase para que explique a los estudiantes cómo él solamente representaba a un personaje y que no es él mismo el personaje.

Si afrontamos críticamente la televisión, podemos convertirla en un instrumento creador de conciencia histórica. En este sentido, el anális is de la telenovela más banal, puede convertirse en un instrumento educativo. Agregando, además, la creación de guiones y dramatizados que tengan como objetivo específico educar en una forma integral y crear una conciencia social.

La prensa es también un medio de comunicación muy importante y, por lo tanto, un instrumento didáctico de primera línea en la enseñanza de la historia ya que es una síntesis de la vida diaria.

El estudiante debe aprender a leer la prensa, debe diferenciar el significado del editorial, de las noticias generales y de las columnas especializadas. Debe investigar a qué personas o grupos representa el periódico, cuál es su ideología o tendencia política, qué objetivos persigue, qué temas son noticia. Qué importancia se le da por el desplegado. En qué parte del país o del mundo hay conflictos. Qué tipos de conflictos, y sus orígenes. Cuáles son las últimas conquistas de la ciencia y de la técnica.

Hasta las páginas sociales, las cartas de los lectores, las caricaturas y los monos, pueden convertirse en medios didácticos. Quiénes salen y quiénes no salen en las páginas sociales. Dónde se reúnen. A dónde viajan. De dónde vienen. Con qué motivos, etc.

${ }^{24}$ GLADYS DAZA H., (Coordinadora), Cultura de la Imagen, Bogotá, CEDAL, 1990, pág. 16. 
La caricatura es un instrumento formidable en la formación política. Una sola caricatura puede hacer más mella que todo un libro. Puede darse el caso ele altos funcionarios públicos que tengan que renunciar, teniendo como causa inmediata de su renuncia una caricatura.

Los monos son también la expresión de un contexto social y de una mentalidad determinada, aunque se les adobe con leyendas y anacronismos.

Es importante al utilizar la prensa que los estudiantes tengan oportunidad de analizar periódicos de diferentes tendencias, de diversas corrientes ideológicas para que así ellos puedan apreciar cómo se elaboran o se presentan los mensajes en función ele los diversos intereses que controlan el periódico ${ }^{25}$.

Los libros de texto tienen gran importancia si se abordan críticamente y cuando se toman como un instrumento más y como una guía de la enseñanza. De lo contrario, si se les toma como textos únicos que no permiten la investigación, que no presentan opciones diferentes, que proponen ejercicios, la mayoría de los cuales presentan un carácter formalista y, a menudo de tipo memorístico, no valen la pena porque meten a los alumnos en el callejón sin salida de un dogmatismo irreductible. Así lo expresan algunos es pecialis tas en la materia cuando dicen:

El texto escolar, sobre todo si es único y aprendido de memoria, impide la comunicación real y embota toda posibilidad de crítica. Entra plenamente en la educación bancaria estigmatizada por Freire.

Si no es único, favorece el trabajo personal del alumno, pero no neœsariamente su espíritu crítico, si los textos proceden de fuentes semejantes, con parecido enfoque de la realidad ${ }^{26}$.

Los museos son también instrumentos importantes en la enseñanza de la historia, siempre y cuando seamos conscientes de sus limitaciones.

El museo nos permite un contacto directo con objetos de la época estudiada. Pero no toda la historia es tá en el museo, ni siquiera una mínima parte.

Es productivo si sirve para damos cuenta de los cambios en el modo de vida de la gente, viendo si los objetos son representativos de la vivencia de todo el conglomerado social o si sólo representan a un pequeño grupo o a un solo individuo, lo cual no los haría indicadores del modo ele vida de la sociedad toda...

Una comunidad con conciencia histórica, es una comunidad que entiende su presente, como parte del pasado, como una herencia que tiene que aceptar y reconstruir, no como una herencia absoluta que hay que aceptar y repetir pasivamente, sacralizandola hasta el extremo de afirmar explícita o

\footnotetext{
${ }^{25}$ Véase JUAN VIOQUE, La utilización de la prensa en la escuela, Madrid, CINCEL, 1984.

${ }^{26}$ AUTORES VARIOS, Los libros de texto en América Latina, México, Nueva Imagen, 1977, pág. 53.
} 
implícitamente, que no hay futuro brillante si no es como una repetición del pasado. "Todo pasado fue mejor" es el lema del regreso. Es la renuncia a construir el futuro. Es hacer y enseñar his toria de hombres importantes, con sus hechos y fechas respectivas. Es enseñar pasados muertos sin vínculos con el presente. Y con ello los estudiantes se aburren, pierden un tiem po precioso de su vida y no le encuentran sentido a lo que estudian.

Como resultado de lo anterior, no es posible en el campo de la historia una reflexión crítica sobre el pasado que genere una praxis sociopolítica para mejorar nuestra organización social. Es decir, la enseñanza ele la historia no genera una conciencia histórica, sino una conciencia mítica que acepta pasivamente la realidad como algo intocable, como algo que obedece a la ciega voluntad de entidades metafísicas o a leyes naturales invariables.

Pero este tipo de enseñanza de la historia es sacudida a cada paso por una realidad que se nos muestra continuamente más conflictiva y más acelerada en su cambio. Entonces, lo que decimos como maestros, no coincide con la realidad y nuestro discurso docente se convierte en algo vacío cuya función inmediata es sostener un oficio y cuya función mediata es sostener inalterable el orden social vigente.

Ahí la enseñanza de la historia pierde sentido y se hace necesario darle un vuelco al proceso, para fomentar en el educando, a tra vés de dicha enseñanza, el surgimiento de una conciencia crítica y solidaria que lo conduzca a desarrollar una praxis de transfomación social. Pero, para ello es necesario superar el idealismo de que ha estado impregnada la ens eñanza de una historia mítica y tener claro el hecho de que un conocimiento que no tenga como finalidad la transformación del mundo, es un conocimiento que no tiene sentido.

Para term inar, quiero abordar brevemente un acontecimiento histórico, del cual, buena parte del mundo occidental habla en estos días. Me refiero, obviamente al llamado Descubrimiento de América cuyo cumpleaños número quinientos será el año entrante.

¡Polémica la que se ha desatado por la celebración de los quinientos años!

Los es pañoles y los hispanófilos, desean celebrarlo porque, desde su punto de vista, el descubrimiento significa la entrada de todo un continente al mundo de la civilización cristiana y el crecimiento y expansión de la hispanidad. Así lo han enseñado tradicionalmente los libros de texto. Uno ele ellos, todavía en uso en nuestras escuelas, como texto de Historia Patria, comienza así la citada his toria:

El 12 de octubre de 1492, Cristóbal Colón descubrió el Nuevo œntinente, es decir lo que hoy Ilamamos América. El gran Descubridor hizo quatro viajes a estas regiones, pero sólo en el último llegó hasta las playas de lo que se llama hay Colombia.

Encontró estas nuevas tierras pobladas de indígenas. Era preciso implantar entre ellos la civilización, y éste es el trabajo que se inicia durante la Conquista, época en que vinieron de 
España al Nuevo Mundo, soldados y familias que, poco a poc, fueron descuajando las selvas y echando las bases de las primeras poblaciones ${ }^{27}$.

Los indígenas e indigenistas no desean celebrarlo; para ellos significó la destrucción de las culturas indígenas y de los indígenas mismos, y fue una invasión que conllevó el despojo y la barbarie. Un texto de ese tipo escrito en estos días, comienza así el relato:

Esa trágica historia de desolación, muerte y dolor para nuestros ancestros indígenas, se inicia el 12 de octubre de 1492, cuando en el horizonte se avistaron unas gigantescas embarcaciones que desembarcaron en una de las inmensas playas del Caribe.

Aquel día temina la época de esplendor indígena y comienza la historia del saqueo, del robo, del ultraje, de la deculturación, del culto al oro y a la propiedad privada.

Los europeos, que dicen profesar una religión civilizada y respetuosa del hombre — la cristiana en realidad sólo se guían por el oro y la codicia que el oro y la plata despiertan en sus almas ${ }^{28}$.

Como vemos, tenemos aquí dos interpretaciones polarizadas del mismo acontecimiento. $\mathrm{Y}$ dos interpretaciones que nos muestran cómo influyen los intereses del presente en la interpretación del pasado.

A la pregunta de si deben celebrarse los quinientos años del descubrimiento, los alumnos de bachillerato contestan:

Si, porque es un pasaje de la historia que tiene mucha importancia.

Sí, porque es una fecha importante tanto para América como para España.

Sí, para homenajear a los indios que murieron en el descub rimiento.

No, porque vinieron a explotarnos y a esclavizarnos y a hacernos inferiores a ellos.

No, porque sería celebrar la muerte y esclavitud de todos los indígenas de América.

Sí, se debería celebrar, porque, a pesar de todo, los españoles nos dieron un idioma, una religión y nuevas costumbres.

No, porque los conquistadores acabaron con nuestra cultura aunque sea uno de los mejores hechos ${ }^{29}$.

Y un estudiante universitario, nos resume así sus experiencias sobre la visión del descubrimiento:

Cuando yo estaba en primaria se me dijo que los españoles eran buenos porque vinieron a catequizar a los indígenas que estaban en manos del diablo; en bachillerato se me dijo que tenían un defecto: que habían golpeado a algunos indígenas, pero para resarcir esta falta habían traído a

${ }^{27}$ F.T.D.H.H. MARISTAS, Colombia nuestra patria, historia, Cali, Editorial Norma (s. f.), pág. 13.

${ }^{28}$ AUTORES VARIOS, 12 de Octubre de 1492. ¿Descubrimiento o Invasión?, Bogotá, Instituciones varias, 1988, pág. 26.

${ }^{29}$ Cuestionarios contestados en el Colegio Distrital República de Panamá por alumnos de Noveno Grado, Bogotá, 1991. 
algunos negritos para que hicieran progresar el continente por las vías del cristianismo. Esto según los textos y mis maestros. Pero después empece a leer libros; no de texto sino de literatura, política o economía y éstos me informaron que los españoles eran unos explotadores; pero se ensañaron contra éstos y me dejaron con la cabeza caliente y sembraron en míla cizaña contra los verdugos de la península. Creo que se me dieron muchos argumentos, pero no se me dieron bases para tomar una posición con criterio ${ }^{30}$.

Hispanismo e indigenismo excluyentes. Tal vez los españoles tengan razón, desde su punto de vista. Los indígenas también, de acuerdo con el suyo. Y es que, españoles e indígenas estaban ahí en el descubrimiento o en la invasión. En el encuentro, como lo llamamos nosotros.

Pero NOSOTROS, los MESTIZOS en el más am plío sentido de la palabra, la mayoría de los habitantes latinoamericanos, no estábamos ahí. Nacimos después de ese momento. Somos el resultado de ese encuentro. El descubrimiento o la invasión, son nuestra partida de bautismo. Y mal hacemos cuando tomamos una posición como indígenas negando a los españoles porque, gústenos o no, también somos hijos de España, herederos de una cultura que es, mayoritariamente, la cultura hispánica.

Hablamos su idioma, creemos en su Dios o lo negamos; hispánicamente pensamos el mundo con su filosofía, nos vestimos con su moda, llevamos sus nombres y sus apellidos y tenemos unos valores y unas creencias heredadas de España.

Lo anterior no impide que denunciemos la conquista como un proceso violento, de deculturación y aculturación, pero dentro de ese proceso, heredamos una cultura; no la escogimos, nacimos dentro de ella y, por lo tanto, forma parte de nuestro ser histórico, social y psicológico.

Nadie escoge la cultura en que nace, como nadie escoge a sus padres. $Y$ aunque reniegue de ellos, aunque se cambie el nombre y los apellidos, seguirá siendo hijo de los mismos padres. Así ocurre con la cultura en la que hemos nacido y, por lo tanto, nos parece que no tiene sentido renegar de ella, lo cual no la exime de críticas. Pero esto es otra cosa.

¿Qué ocurriría si negáramos nuestra cultura? Quedaríamos desnudos. Pero aun desnudos seguiríamos siendo hispánicos porque no es lo mismo la des nudez hispánica que la desnudez indígena. El indígena desnudo, no sentía y no siente vergüenza (salvo que se haya hispanizado), nosotros si.

Hechas las anteriores apreciaciones, tal vez podamos afimar que es desde la visión mestiza, des de donde podemos valorar con alguna objetividad, el encuentro de esas culturas, encuentro que marcó un hito en la historia universal.

\footnotetext{
${ }^{30}$ GILBERTO MORENO, Primer Semestre de Ciencias Sociales, U.P.N., 1991.
} 
Este encuentro, desde el punto de vista de la historia-ciencia, podemos verlo como el resultado de un proceso necesario ele expansión europea, que dio al planeta nuevas formas de organización social y de expresión cultural.

Darcy Ribeiro, el gran antropólogo brasileño, lo presenta de esta manera:

La historia del hombre en los últimos siglos, es principalmente la historia de la expansión de la Europa Occidental que al constituirse en núdeo de una nueva civilización, se lanzó sobre todos los pueblos de la tierra en oleadas sucesivas de violencia, de codicia y de opresión. En este movimiento el mundo entero fue revuel to y recompuesto de acuerdo con los designios europeos y conforme a sus intereses. Cada pueblo y aun cada individuo dondequiera que hubiese nacido y vivido, fue finalmente alcanzado y envuelto en el ordenamiento europeo y en los ideales de riqueza, poder, justicia o santidad, por el inspirados ${ }^{31}$.

En este proceso de europeización del mundo, también nos llega el hombre africano, trabajador incansable, sufrido y alegre; con la música en sus venas. También él hace su aporte al mestizaje.

Des de el punto de vista del contexto histórico, la conquista y la colonización se dieron como los conocemos porque no había alternativas viables.

Las estructuras económicas, sociales, políticas e ideológicas de la España de entonces, no admitían nada distinto a lo que ocurrió.

No era una cuestión deliberada de unos cuantos individuos o del rey. A ese nivel tenemos la lucha del Padre Bartolomé de Las Casas, del Obispo Vasco de Quiroga, de gran cantidad de religiosos especialmente dominicos y franciscanos, y la buena voluntad de algunos reyes, comenzando por la hoy tan cuestionada Isabel la Católica. Todos ellos trataron de defender a los indios de la esclavitud y de la servidumbre, logrando muy poco en la práctica. El imperio no hubiera funcionado sin la mano indígena y africana. Esa es la realidad his tórica.

Tampoco hay que pensar que las otras potencias conquistadoras $y$ colonizadoras, lo hicieron mejor en el resto del mundo. Afirmar esto es desconocer la historia de la dominación europea.

Hay quienes, por no conocer la historia, suspiran o maldicen por no haber sido descubiertos por los ingleses o los holandeses u otros europeos no ibéricos.

El otro día, me encontré en un periódico de primera línea a nivel nacional, una carta de un lector que dice:

Estoy invitando y planteando un desafío a todos los importantes autores colombianos y extranjeros para que escriban el libro que nos aclare y denuncie qué vamos a celebrar en el quinto œntenario del Descubrimiento español: ¿la destrucción y violación de nuestras tribus y culturas? ¿El pillaje de nuestros recursos y riquezas? ¿La siniestra categoría humana de nuestros conquistadores? ¿ La desastrosa herencia étnica que llevamos en la sangre, de

31 DARCY RIBEIRO, Las Américas y la Civilización, Buenos Aires, Centro Edit. de América Latina, 1969, Tomo I, pág. 63. 
violencia, injusticia social, feudalismo, intransigencia, insensibilidad ecológica, mala fe, pereza, indisciplina, anarquía, improvisación, irresponsabilidad, picardía, juego, jolgorio, herencia que ha marcado a todas las naciones hispanoamericanas con el baldón del subdesarrollo, de paisaje de tercero y último mundo? ¿Que vamos a œelebrar? Lamentamos, en 1992, eso sí, el que hace 500 años, funestos vientos marinos desviaran los barcos holandeses, noruegos, ingleses y daneses, que navegaban hacia nosotros. Seríamos mejores ${ }^{32}$.

Todo lo anterior es arrojar el baldón de la ignominia sobre todo lo que es hispánico; sobre toda la herencia his pánica. Otro as pecto en el cual se deforma la historia del encuentro, es considerar que las culturas indígenas eran de una perfección paradisíaca y que los indígenas vivían en completa amonía.

El texto indigenis ta que he citado antes, afirma al respecto: "La conquista es un proceso de destrucción material y cultural. Es pisotear en forma arbitraria el legado legendario de los grupos indígenas que han convivido armoniosamente durante cuarenta mil años en el continente americano" ${ }^{\text {"33 }}$.

Cualquiera que haya estudiado seriamente historia prehispánica sabe que los indígenas se hacían la guerra y se dominaban unos a otros. Las enemistades surgidas entre ellos, sirvieron a Hernán Cortés y a Francis co Pizarro para dominar a los imperios azteca e inca, con la ayuda, muy notable, de indígenas aliados.

A nivel interno, en esas grandes culturas había ya una diferenciación social que había llevado al establecimiento de una nobleza privilegiada en un polo y a la existencia de esclavos o sirvientes, en el otro. $Y$ por supuesto, al inicio del surgimiento de la propiedad privada.

Y cuando uno encuentra escritos que atacan al idioma español (en español), por haber sido impuesto a los nativos, despojándolos de sus propias lenguas, la memoria tiene que recordar lo que hacían los incas cuando "incaizaban" poblaciones enteras que eran, desarraigadas de sus territorios ancestrales para ser trasladadas a otras regiones ya incaizadas en donde se les imponían el idioma yel culto a los dioses y a las formas de vida del imperio incaico.

Finalmente entonces, ¿qué nos queda? ¿Renegar de nuestra cultura porque fue impuesta? Si así fuera, tendrían que renegar de su cultura casi todos los pueblos de la tierra, comenzando por los mismos ibéricos a quienes los romanos impusieron la suya, y donde los visigodos y los árabes dejaron buena herencia. Contra los romanos tendrían que renegar también otros pueblos como los galos, los anglosajones y los gemanos. Los rusos deberían renegar del Imperio Bizantino que les impuso la religión y el alfabeto. Los iraníes deberían renegar de los árabes que impusieron allí el islamismo en el cual hoy creen fanáticamente...

Es cierto que Europa saqueó al mundo, explotó a millones de seres humanos, a muchos los convirtió en mercancías; eso hay que denunciarlo y hay que

32 “HERNANDO VILLALBA, “¿Qué celebramos?” El Tiempo, 23 de abril de 1991, pág. 18

33 Autores Varios, 12 de Octubre de 1492, p. cit., pág. 44 
condenarlo; pero también es cierto que allí, en la misma Europa, brotaron los primeros gritos de libertad, igualdad y fraternidad. Alí se escribieron los primeros textos sobre los derechos del hombre, valores con los cuales hoy continuamos la lucha quienes queremos dejar el mundo un poco mejor de lo que lo encontramos.

1992 nos servirá para recordar el encuentro de dos culturas, la incorporación posterior de una tercera, y el surgimiento de la raza mestiza, a partir de ese momento. Será la oportunidad para valorar mejor, desde el mestizaje, a nuestras culturas madres: la indígena, la hispánica y la africana, investigando a fondo el aporte de cada una de ellas, con sus deficiencias y con sus virtudes, con sus sueños y con sus pesadillas, con sus traumatismos y con sus esperanzas.

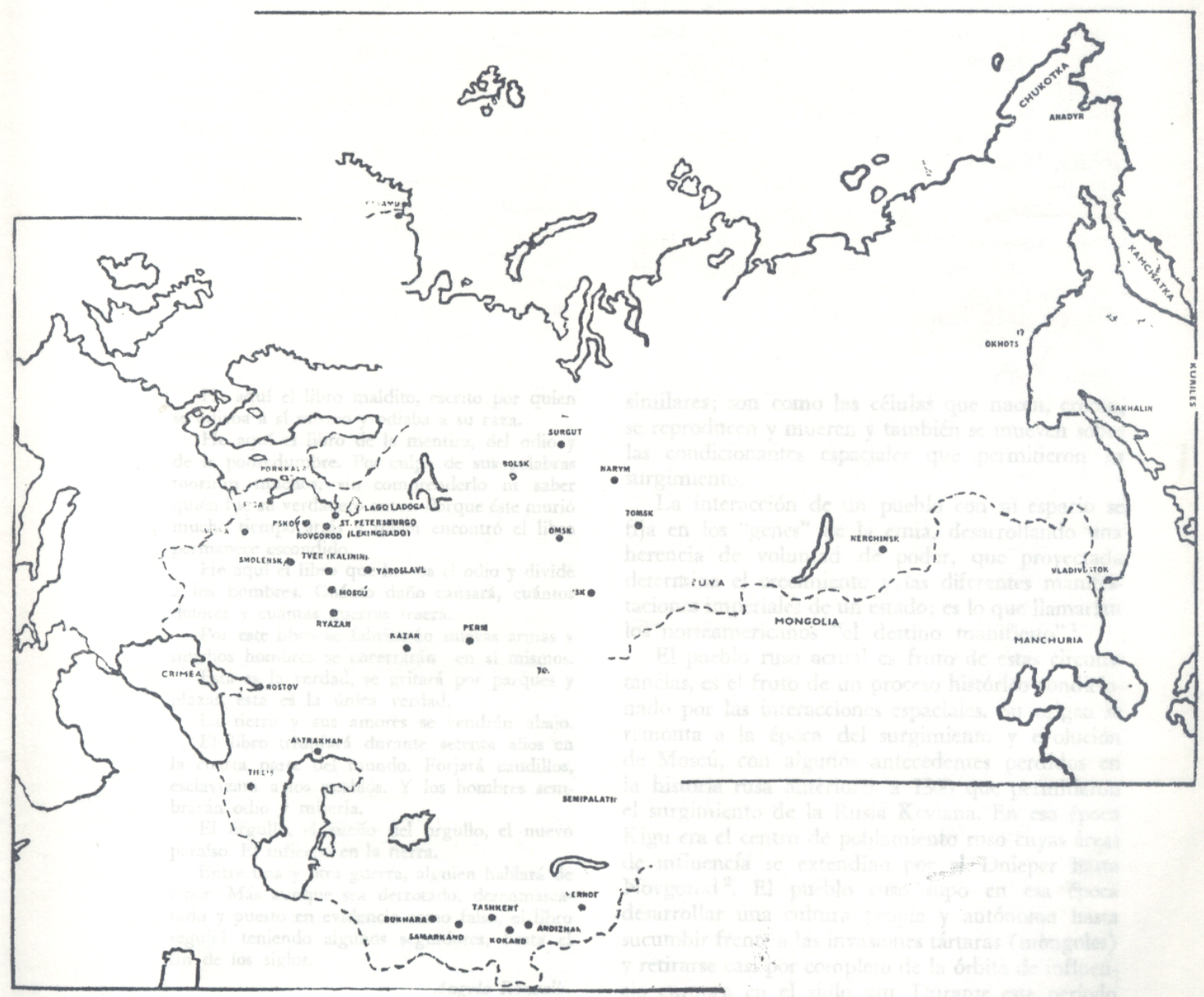

